\title{
O ALUNO NA POSIÇÃO \\ DE AUTOR: UMA EXPERIÊNCIA \\ COM A RESENHA NA \\ UNIVERSIDADE
}

\section{EL ALUMNO EN LA POSICIÓN DE AUTOR: UNA EXPERIENCIA CON LA RESEÑA EN LA UNIVERSIDAD}

STUDENTS AS AUTHORS: AN EXPERIENCE WITH REVIEWS IN THE UNIVERSITY

\author{
Sandro Braga* \\ Universidade Federal de Santa Catarina \\ Janaína Senem** \\ Secretaria de Estado da Educação do Paraná
}

\begin{abstract}
RESUMO: Apresentamos uma reflexão acerca dos modos de o sujeito ocupar a posição de autor na escrita acadêmica a partir de sua participação no Laboratório de Leitura e Escrita Acadêmica (LABEAL/UFSC). Partimos dos pressupostos teóricos da Análise do Discurso de inspiração francesa, para compreender como o sujeito se inscreve, enquanto autor, quando escreve em uma escrita que visa a "objetividade científica". Elegemos para análise a escrita e a reescrita de uma resenha produzida no LABEAL, tendo em vista as mudanças que ocorrem da primeira para a segunda escrita no que concerne à autoria nessas produções. No gesto analítico, investe-se em mostrar como o processo de escrita na academia consiste e insiste numa tentativa de "conter" a heterogeneidade constitutiva do discurso e do sujeito, na luta pela transparência da linguagem e dos sentidos em nome do discurso científico. Nesse processo, em busca da objetividade, o sujeito procura se constituir assumindo diferentes posições, conforme as condições de produção, e tentando se situar no entremeio aceitável que configura a função-autor na universidade.
\end{abstract}

PALAVRAS-CHAVE: Produção textual. Escrita acadêmica. Autoria.

RESUMEN: Presentamos una reflexión acerca de los modos de que el sujeto ocupa la posición de autor en la escritura académica a partir de su participación en el Laboratório de Leitura e Escrita Acadêmica (LABEAL / UFSC). Partimos de los presupuestos teóricos del Análisis de Discurso de inspiración francesa, para comprender cómo el sujeto se inscribe, como autor, cuando escribe en una escritura que apunta a la "objetividad científica". Elegimos para análisis la escritura y reescritura de una reseña producida en el LABEAL, teniendo en vista los cambios que ocurren de la primera a la segunda escrita en lo que concierne a la autoría en esas producciones. En el gesto analítico, se invierte en mostrar cómo el proceso de escritura en la academia consiste e insiste en un intento de "contener" la heterogeneidad constitutiva del discurso y del sujeto, en la lucha por la transparencia del lenguaje y de los sentidos en nombre del discurso científico. En este proceso, en busca de la objetividad, el sujeto procura constituirse asumiendo diferentes

\footnotetext{
* Professor no Programa de Pós-graduação em Linguística da Universidade Federal de Santa Catarina. Coordenador do LABEAL/UFSC. E-mail: sandrocombraga@gmail.com

** Professora na Secretaria de Estado da Educação do Paraná. Mestre pela Universidade Federal de Santa Catarina. Email: janaina.f.senem@gmail.com
} 
posiciones, conforme a las condiciones de producción, e intentando situarse en una entremezcla aceptable que configure la función autor en la universidad.

PALABRAS CLAVE: Producción textual. Escritura Académica. Autores.

ABSTRACT: We present a reflection about the ways in which the subject occupies the author's position in academic writing through his participation in the Laboratório de Leitura e Escrita Acadêmica (LABEAL/UFSC). From theoretical assumptions of the French Discourse Analysis, we seek to understand how the subject signs himself as author, when he writes aiming "scientific objectivity". Thus, we analyze the writing and rewriting of a review produced in the LABEAL focusing specially on the changes that occur from the first to the second writing with regard to authorship in these productions. In the analytical gesture, undertaken so far, we seek to show how the process of writing in academy consists and insists in an attempt "to contain" the constitutive heterogeneity of discourse and subject, in the struggle for the transparency of language and the senses in the name of scientific discourse. In this process, aiming for objectivity, the subject seeks to be constituted by assuming different positions, according to the production conditions, and trying to place himself in an acceptable gap that configures the author function in university.

KEYWORDS: Text production. Academic writing. Authorship.

\section{INTRODUÇÃO}

Escrever na universidade não é uma tarefa simples e muitos alunos, ao ingressarem na graduação e na pós-graduação, encontram dificuldades para se situar nesse lugar que requer um efeito de objetividade na escrita. Desse modo, este trabalho se justifica ao problematizar a questão da inscrição do sujeito na escrita acadêmica, tendo em mente a assunção à autoria do aluno no âmbito da universidade, através da análise de uma escrita e reescrita de uma resenha produzida no Laboratório de Leitura e Escrita Acadêmica (LABEAL | UFSC). Assim, almejamos compreender os movimentos que incidem maior ou menor gesto de autoria na constituição do sujeito que se põe a dizer na produção do texto acadêmico a partir da concepção de heterogeneidade enunciativa de AuthierRevuz (1990), e analisar como se constituem o discurso acadêmico e o científico na produção desses textos.

A escolha dessa problemática que contempla os modos de o sujeito ocupar uma posição na escrita acadêmica, alçado pela funçãoautor, parte das práticas vivenciadas no Laboratório - visto que muitos alunos, ao procurarem esse espaço, afirmam ter dificuldades para se situar nessa escrita - e das justificativas ${ }^{1}$ apontadas como mote para a procura da assessoria do LABEAL: "Aperfeiçoar a escrita acadêmica", "aprender a escrever", "melhorar a escrita", "reaprender a escrever", "sanar dificuldades em relação à produção do texto dissertativo", "aprimorar minha escrita para artigos", entre outros dizeres que reverberam um imaginário acerca da complexidade da escrita que se situa entre o discurso científico e o acadêmico.

Percebemos, então, que esses dizeres estão associados a uma visão de língua como transparente, neutra e objetiva, sobretudo aquela que parece configurar o discurso científico, uma vez que esse discurso almeja a manutenção de uma "pureza científica". Ou seja, uma linguagem destituída do sujeito que diz e que se centra no próprio objeto que refere. Essa visão de língua, a partir da Análise do Discurso, se institui como uma ilusão, pois não se pode pensar em discurso sem sujeito e, consequentemente, sem ideologia. Assim, dizer, mesmo na escrita acadêmica, implica um modo de o sujeito mobilizar a língua, e essa língua revela tanto a produção de sentido ao referente quanto o próprio sujeito constituído sócio-historicamente que se põe a dizer nesse ato.

\section{DISCURSO, SUJEITO E FUNÇÃO-AUTOR}

Sabe-se que a linguagem nos constitui, que ela opera em uma relação de dispersão e unidade (discurso e texto) e que todo uso da língua implica em diferentes formas de significação da própria língua e da constituição do sujeito. Nesse sentido, o discurso não pode ser imaginado linearmente, como uma linha que segue uma direção e que não apresenta rupturas; ele é dispersão, no sentido de que não está organizado em uma direção rumo a um ponto final, e constitui todas as relações que envolvem linguagem, tanto

${ }^{1}$ Essas justificativas estão presentes nos formulários que os alunos preenchem ao ingressar no Laboratório. 
verbal quanto não verbal. Desse modo, a Análise do Discurso de vertente francesa se constitui como um campo em que o funcionamento da linguagem é pensado como relação entre posições-sujeito que são afetadas histórica e ideologicamente e que, nos processos intersubjetivos, filiam-se a certos efeitos de sentido e não a outros. Assim, conforme Pêcheux (1990, p. 82 [1969]), o discurso é entendido como "efeito de sentidos entre interlocutores".

Nessa perspectiva teórica, Orlandi (2013, p. 17) afirma que “[... não há discurso sem sujeito e não há sujeito sem ideologia [...]”. Dessa forma, o sujeito não é compreendido como o indivíduo empírico, mas sim como sujeito do discurso que ocupa diferentes posições de acordo com diferentes condições de produção. Como bem coloca Orlandi (2013, p.49): "Ele é sujeito de e é sujeito à. Ele é sujeito à língua e à história, pois para se constituir, para (se) produzir sentidos ele é afetado por elas. Ele é assim determinado, pois se não sofrer os efeitos do simbólico, ou seja, se ele não se submeter à língua e à história ele não se constitui, ele não fala, não produz sentidos".

Nesse sentido, o sujeito é determinado, ou "assujeitado" à língua, à história, ao inconsciente e à própria ideologia, mas também é livre dentro dessas delimitações que lhe são impostas. Em outras palavras, a relação do sujeito com o discurso, com a história e com a ideologia se situa em uma relação de liberdade com responsabilidade e, de certo modo, é condicionada pelas conjunturas e possibilidades de ser sujeito.

Se entendemos o sujeito como ideológico, é preciso compreender que a ideologia se caracteriza por uma estrutura-funcionamento que o constitui inexoravelmente. Isto é, a ideologia interpela o indivíduo em sujeito e o sujeito, como posição no discurso, colocase a dizer de um determinado lugar, lugar esse constituído por formações discursivas que representam as formações ideológicas. As formações discursivas, em resumo, determinam aquilo que pode e deve ser dito em um determinado momento histórico. O processo discursivo se dá, desse modo, em uma relação de implicação de aspectos exteriores à materialidade linguística em que as formações discursivas materializam as formações ideológicas que manifestam a ideologia e que, por sua vez, se materializa no discurso. Além disso, todo o processo de interlocução é intersubjetivo e, portanto, envolve o imaginário. Nesse sentido, além das formações ideológicas e da própria ideologia, as formações discursivas são constituídas também pelas chamadas formações imaginárias, que consistem na visão que um sujeito tem sobre o outro de sua interlocução e também sobre a visão que esse sujeito acredita que esse outro tem de si mesmo. Esse imaginário afeta a forma como se desenrolam as manifestações discursivas e o posicionamento do sujeito em diferentes interlocuções. Todas essas noções estão imbricadas no processo de constituição de sentidos e, também, na inscrição do sujeito em seu dizer.

Para pensar na inscrição (ou não) do sujeito na escrita acadêmica, pensamos em sua constituição como autor, entendendo a autoria como constitutiva do texto e, consequentemente, presente em toda prática discursiva que suscita a responsabilidade daquele que diz por aquilo que diz. Assim, “[...] a noção de autor é já uma função da noção de sujeito, responsável pela organização do sentido e pela unidade do texto, produzindo o efeito de continuidade do sujeito." (ORLANDI, 1996, p. 68-69). A assunção à autoria se caracteriza, então, nesse processo em que um sujeito inscrito em uma determinada posição procura organizar seu dizer, de forma coerente e com efeito de fecho, de unidade, e assume a responsabilidade por essa organização (ORLANDI, 2013).

Tendo isso em mente, a assunção à autoria é compreendida como gesto de interpretação do sujeito que organiza seu dizer com base no já-dito (interdiscurso ${ }^{2}$ ), ou seja, "[o] sujeito só se faz autor se o que ele produz for interpretável. Ele inscreve sua formulação no interdiscurso, ele historiciza seu dizer.” (ORLANDI, 1996, p. 70). Nessa acepção, entende-se que a repetição possibilita a interpretação e que essa se dá pela possibilidade histórica.

Imbricada à noção de autoria está a concepção de texto, visto que "[...] a autoria não é uma qualidade, mas uma prática na configuração de um texto." (LAGAZZI-RODRIGUES, 2015, p. 109). Nessa perspectiva, o texto não é entendido sob a lógica da linguagem transparente, em que o sentido já está posto, cabendo ao leitor descobri-lo. Para a Análise do Discurso, o texto é materialidade histórica e deve ser compreendido em sua relação com outros textos, com as condições de produção e com o

${ }^{2}$ Orlandi (2013) define interdiscurso, com base em Pêcheux, como o já dito, ou, ainda, a memória discursiva. Nesse sentido, ele é da ordem do repetível, da constituição do dizer. Para Pêcheux (2014 [1988]), o interdiscurso é da ordem de um pré-construído dominante das formações discursivas que por sua vez dissimula o sentido como sendo transparente na linguagem. 
interdiscurso. Assim, “O texto é essa peça significativa que, por um gesto de autoria, resulta da relação do 'sítio significante’ com a exterioridade. Nesse sentido, o autor é carregado pela força da materialidade do texto, materialidade essa que é função do gesto de interpretação (do trabalho da autoria) na sua relação determinada (historicamente) com a exterioridade, pelo interdiscurso." (ORLANDI, 1996, p. 15).

Desse modo, uma análise sob a perspectiva discursiva atenta para o texto enquanto unidade, materialidade linguística e histórica que produz efeitos de sentido. É através da análise dos efeitos de sentido que se pode perceber o funcionamento do discurso, as formações discursivas, imaginárias e ideológicas que ali operam. Além disso, para esta proposta analítica, é interessante pensar nessa relação entre texto e autoria na escrita acadêmica, pois se o trabalho da autoria consiste em um gesto de interpretação sobre o texto e o texto se situa em uma relação com a exterioridade, a exterioridade do discurso acadêmico opera na constituição da autoria e dos textos produzidos nessa esfera. É justamente sobre essa exterioridade que trataremos no tópico a seguir.

\section{A VERDADE E A CIÊNCIA NA RELAÇÃO SABER-PODER}

Tendo como pressuposto as proposições do campo da Análise do Discurso, não se pode pensar em qualquer situação que envolva o uso de linguagem sem fazer remissão às condições de produção que tal prática social aponta. Na escrita acadêmica, isso não pode ser pensado de forma diferente. Isso porque são as condições de produção que possibilitam a produção de sentidos que se entrelaçam com a memória (interdiscurso) e se situam em uma (ou mais) formação(ões) discursiva(s). Assim, procuramos refletir sobre os modos de funcionamento da escrita acadêmica, tendo em vista a constituição e o funcionamento do discurso científico e do discurso acadêmico.

De início, ressaltamos que, sob a perspectiva que assumimos, a escrita é entendida como uma prática social sempre concretizada a partir das relações entre o sujeito-autor que escreve e o leitor (PEREIRA, 2013). Ainda sobre essa concepção de escrita, Pereira (2013) afirma que a escrita é também algo que as pessoas fazem para si mesmas ${ }^{3}$. Assim, é pelo próprio processo de escrita, no qual se organiza o pensamento, que se pode mudar de direção, tomar outros rumos (ou ainda criar um rumo) e desenvolver ideias, conceitos (PEREIRA, 2013). Nessa acepção, podemos nos perguntar: Como se dá a escrita no âmbito acadêmico? Como os sujeitos se inscrevem nessa prática e quais as dificuldades de tomar voz nessa prática social tão fortemente marcada pelo institucional?

A escrita acadêmica, conforme aponta Pereira (2013), é um dos grandes pontos que diferencia a ciência das outras formas de saber. A ciência e seu compromisso com a validação, com a verdade e com a posição que ocupa de legitimação optou em apagar o sujeito em nome de uma neutralidade inatingível "[...] como se o texto científico pudesse se elevar para além do mundo e da história" (PEREIRA, 2013, p. 216). Dessa forma, o discurso da ciência vê a linguagem como transparente e acaba por ignorar as condições históricas e ideológicas que perpassam a constituição dos discursos e, concomitantemente, a constituição do sujeito. Assim, "O mundo da ciência fez disseminar a ideia de que éramos capazes de controlar a verdade por intermédio do controle do discurso: apoiados na pretensão de controlar o discurso e sua origem, os cientistas desconsideravam que a gênese da linguagem, do discurso e da escrita é a própria história." (PEREIRA, 2013, p. 217).

Nesse sentido, ao tirar a história, a ciência "apaga" também o sujeito que diz, buscando estabelecer um efeito de neutralidade entre realidade e linguagem na qual essa só teria a função de retratar aquela. Dessa forma, a ciência aponta para uma visão da língua como representação do mundo material em que a escrita é somente um meio para se alcançar o que de fato significa: o objeto (PEREIRA, 2013).

Essa visão de língua como objetiva, não sujeita a falhas, desistoricizada, que exclui o sujeito que diz, é aquela com que muitos alunos se deparam ao adentrar na universidade.

\footnotetext{
${ }^{3}$ No sentido abordado, não significa que não haja sempre um "para quem" da escrita, pelo contrário, como prática social ela sempre está engajada nesse processo de relação com o outro. Entretanto, esse uso que as pessoas fazem da escrita para "si mesmas", que também implica o outro, é no sentido da própria construção do pensamento que se dá nessa prática social, conforme Pereira (2013).
} 
A partir do exposto, somos levados a pensar que as condições de produção que permeiam os discursos científicos parecem colocar o sujeito em um entre-lugar no qual ao mesmo tempo em que se instaura a necessidade de dizer algo novo, tendo em vista a competitividade e produtividade científica, esse dizer deve apagar a voz daquele que diz em nome de uma manutenção da verdade, de uma "pureza" científica (LYOTARD, 2009 [1979]). Em outras palavras, é dizer algo novo e não se mostrar presente, como se fosse possível alcançar uma neutralidade na linguagem. O dito destituído do eu que diz.

A competitividade científica que leva à necessidade de dizer algo novo é pensada também através da relação entre saber e poder, uma vez que o saber é um mecanismo de poder (FOUCAULT, 1989 [1979]). Assim, há uma luta "[...] em torno do estatuto da verdade e do papel econômico-político que ela desempenha." (FOUCAULT, 1989 [1979], p. 13).

Nesse sentido, o político faz parte da constituição do discurso científico e, como estamos propondo a análise de textos resultante de práticas do nosso próprio trabalho com a escrita acadêmica que se constitui pelo discurso da ciência, é necessário olhar para essas condições de produção que permeiam esse texto; nesse caso específico, a resenha. Assim, é de suma importância observar que as resenhas produzidas no Laboratório de Escrita Acadêmica e Leitura são perpassadas, também, pelo discurso acadêmico. Dessa forma, surgem questões que demandam reflexões ainda não formuladas: Como se constituem o discurso científico atravessado por um outro discurso, neste caso, o acadêmico? Quais seriam os pontos de aproximação e de distanciamento entre esses dois tipos de discursos, muitas vezes, tomados como sinônimos?

\section{A ESCRITA QUE SE INSCREVE ENTRE O CIENTÍFICO E O ACADÊMICO}

Ainda com o ensejo de tentarmos caracterizar a escrita acadêmica, faz-se necessário, primeiramente, delimitarmos que tipo de escrita acadêmica tomamos como objeto. Sob esse prisma, é preciso identificar quem é o sujeito que está posto nessa condição de produção de texto, bem como qual é o objetivo e o endereçamento dessa escrita. Dito de outro modo, é preciso levar em conta se aquele que escreve alça de um estatuto de pesquisador (titulado e já colocado profissionalmente) ou se é um estudante (neste caso, de graduação? De mestrado? De doutorado?), e com que finalidade escreve: para publicação em periódicos científicos, livros teóricos ou para atender à demanda de uma disciplina com vistas à avaliação do texto e, por conseguinte, do estudante.

Apontadas essas implicações de "quem escreve?" e "para que escreve?", assinalamos que nosso interesse com a escrita acadêmica é com aquela fruto, produto, resultado do modo de escrever realizado pelo sujeito que se encontra na posição de aluno universitário e que tem por fim a escrita acadêmica compreendida como ascensão ao discurso científico. No entanto, o modo de apropriação e de inscrição nesse discurso da ciência - materializado a partir da entrada no discurso acadêmico - acontece agenciado no âmbito do processo de ensino e aprendizagem dessa escrita, ou seja, atravessado pelo modo de funcionamento, também, do discurso pedagógico. Dessa forma, para compreendermos o modo de operar a palavra nessa escrita, propomos pensá-la como uma prática que se realiza entre o científico e o acadêmico para inscrever ao discurso científico aquele que escreve na academia.

De início, para compreender o discurso científico (DC) é necessário considerar que, de acordo com Foucault (2013 [1969]), a ciência se constitui de um "campo de possibilidades estratégicas" que se caracteriza como um princípio de formação e dispersão de enunciados que podem ser ditos em um determinado momento histórico, ou seja, que compõem as formações discursivas. Dessa forma, entende-se a ciência como um princípio que possui suas regras de estruturação sintática e semântica, de acordo com o objeto de que se fala, mas, além disso, como possibilidade de se inscrever na história, isto é, como um discurso que se constitui de um grupo de enunciados que são possíveis de serem ditos em um momento histórico (formações discursivas) e que não, necessariamente, tem o mesmo funcionamento do que era compreendido como ciência em um momento anterior.

Nesse sentido, entendemos que o discurso científico pode ser pensado a partir dos procedimentos de controle e de delimitação do discurso propostos por Foucault (2012 [1970]). Sabemos que esses procedimentos constituem diversos discursos, mas acreditamos que, em especial os princípios internos e externos, apontados por Foucault, caracterizam, sobremaneira, o discurso da ciência na medida em que relacionam poder e saber. Os princípios externos - interdição, separação e rejeição, e vontade de verdade - regulam o que pode e deve ser dito, determinam as classificações e categorizações que se realizam pelo e no discurso, tendo em vista o lugar 
discursivo que se pode ocupar. Por exemplo, do lugar de mediadores no LABEAL, podemos dizer certas coisas (e não outras) em relação à escrita acadêmica que o aluno, tendo em vista o imaginário constitutivo do Laboratório como espaço para a produção de escrita acadêmica, imagina que sejam ditas e que a partir de seu lugar como aluno ele não pode dizer. Ainda ressaltamos, desses princípios, que a vontade de verdade está implicada no discurso científico, pois a ciência funda-se implicada com a verdade, sob a ilusão de um dizer verdadeiro, ou seja, um dizer que diz dizer a verdade e essa verdade constrói o saber.

Já os princípios internos - comentário, disciplinas e autoria - são entendidos por Foucault (2012 [1970]) como mecanismos constitutivos dos discursos e que exercem o seu próprio controle e caracterizam o discurso científico. O comentário é compreendido como sendo da ordem de um deslocamento entre um texto primeiro e um texto segundo, está presente em diversas práticas discursivas científicas; a autoria é vista como princípio de agrupamento do discurso e as categorizações das disciplinas emergem do campo a partir do qual o que pode ser dito precisa estar no limite do verdadeiro. Assim, esses procedimentos, no discurso científico, jogam na relação entre poder e saber que sustenta o dizer da ciência como um dizer institucional. Conforme Foucault (1989 [1979], p.12):

O importante, creio, é que a verdade não existe fora do poder ou sem poder [...] A verdade é deste mundo; ela é produzida nele graças a múltiplas coerções e nele produz efeitos regulamentados de poder. Cada sociedade tem seu regime de verdade, sua 'política geral' de verdade: isto é, os tipos de discurso que ela acolhe e faz funcionar como verdadeiros; os mecanismos e as instâncias que permitem distinguir os enunciados verdadeiros dos falsos; a maneira como se sanciona uns e outros; as técnicas e os procedimentos que são valorizados para a obtenção da verdade; o estatuto daqueles que têm o encargo de dizer o que funciona como verdadeiro. (FOUCAULT, 1989 [1979])

Em relação à instituição acadêmica e, em específico, ao Laboratório de Escrita Acadêmica e Leitura, é importante acrescentar que esse espaço se constitui no entremeio do discurso científico (DC) e do discurso acadêmico (DA). No que tange ao modo de funcionamento do discurso acadêmico (DA) no LABEAL, cabe dizer que esse discurso pauta-se pelo dizer da ciência (DC) mas, também, está imbricado, sobremaneira, pelo discurso pedagógico (DP), visto que a escrita acadêmica com pretensões ao científico acontece - nesse espaço - no ponto de confluência do processo de ensino e de aprendizagem dessa escrita. Uma monografia, por exemplo, se insere no discurso acadêmico para produzir o discurso científico, sendo que essa produção se constitui afetada pelas marcas do processo de aprendizagem, que podem ser entendidas como características do discurso pedagógico sobre o acadêmico. Outro exemplo seria a produção de um artigo científico, que pode ou não estar afetado pelo pedagógico. Quando este for tomado como objeto para o estudante "aprender" a caracterização, constituição e produção desse gênero, inscreve-se no acadêmico que versa sobre o científico, mas não descola-se do pedagógico. Já quando o artigo tem como foco primeiro a publicação em periódico científico, insere-se, também, no acadêmico como possibilidade deste dizer sobre a ciência, mas não mais se vê acoplado ao discurso pedagógico - não ao menos como aquele que funciona nos processos de ensino e aprendizagem.

Assim, o discurso acadêmico se relaciona com o pedagógico e não se configura como discurso da ciência necessariamente; portanto, DA e DC não devem ser tomados como sinônimos. Disso apontamos que o discurso acadêmico não é o discurso científico; é um discurso sobre a ciência em que a própria ciência se constitui. A partir do exposto, entendemos que o DA - quando tomado como objeto de ensino e aprendizagem - volta-se para o ensino do discurso da ciência, com o processo de produção de conhecimento e, ao mesmo tempo, constitui a produção científica.

Por fim, reforçamos a ideia de que, no tocante ao trabalho realizado no Laboratório, este se realiza justamente na confluência entre o discurso acadêmico e o científico, uma vez que as práticas de escrita nesse ambiente se configuram na medida em que o sujeitoparticipante se posiciona no discurso acadêmico, afetado pelo discurso pedagógico, visando à produção do discurso da ciência. Essa prática pode ser comparada - ou assemelha-se - àquelas decorrentes da produção da escrita acadêmica solicitadas por professores a por seus alunos na universidade, mas, por outro lado, diferencia-se, de algum modo, da escrita acadêmica que não está afetada por tais processos de ensino e aprendizagem. 
A partir das reflexões que propomos sobre as condições de produção da resenha, partimos para a análise do corpus com o intuito de refletir sobre os modos de o sujeito ocupar a função-autor na confluência desses dois discursos.

\section{PROPOSTA ANALÍTICA DO CORPUS}

Antes de partirmos para a análise da escrita e da reescrita de uma resenha produzida no Laboratório de Escrita Acadêmica e Leitura, é relevante apresentar o modo de funcionamento do LABEAL. Inicialmente, é preciso compreender que o Laboratório, que teve início em 2014, se caracteriza por ser um ambiente que tem como objetivo principal facultar a prática da escrita acadêmica através de atividades de leitura e produção textual para alunos da graduação e da pós-graduação da Universidade Federal de Santa Catarina, no âmbito da extensão universitária. Além disso, o projeto também envolve a pesquisa, a partir dos dados coletados visando discutir (num outro momento e apenas entre os pesquisadores) o processo de produção desses textos sob a ótica discursiva. Desse modo, o trabalho desenvolvido no LABEAL se embasa na produção de gêneros textuais discursivos ${ }^{4}$ próprios da esfera acadêmica para que os alunos possam compreender como eles funcionam, bem como quais são as características que os constituem e, ainda, no reconhecimento das principais dificuldades em operar com um gênero ou outro na universidade. As atividades desenvolvidas no projeto seguem, basicamente, um percurso ${ }^{5}$ : os participantes devem, individualmente, ler um texto, produzir uma atividade de escrita; em seguida, os pesquisadores trabalham junto com o aluno para pensar sobre o texto produzido e os sentidos que ali estão operando; e, com base nesses apontamentos entre pesquisador e aluno, este último parte para uma $2^{\mathrm{a}}, 3^{\mathrm{a}}$ ou $4^{\mathrm{a}}$ atividade de reescrita. A ênfase na reescrita tem por função pensar na escrita como um processo que se constrói e desconstrói, que se ressignifica e que ressignifica o sujeito do discurso.

Como espaço de reflexão sobre o discurso e as formas como ele opera na escrita acadêmica, o Laboratório procura identificar as dificuldades do participante, sejam elas de ordem discursiva ou textual, e propor reflexões com relação a esse tipo de escrita, visando à refacção e também o efeito de unidade textual. Além disso, as atividades procuram nortear possíveis caminhos de leitura para que o participante possa perceber como o texto é construído e de que forma os elementos operam discursivamente na construção de sentidos.

A análise apresentada envolve um recorte da escrita e reescrita de uma resenha produzida no LABEAL sobre uma reportagem veiculada na revista Veja. Optamos por analisar uma resenha, pois, de acordo com os manuais de orientação para a produção de textos acadêmicos, ela é um gênero que tem como finalidade "[...] a divulgação de textos e de obras, informando, em uma perspectiva crítica, o que tais textos e obras contêm. A resenha registra impressões pessoais do resenhista sobre o texto-fonte." (BALTAR; CERUTTI-RIZZATTI; ZANDOMENEGO, 2011, p. 74) ${ }^{6}$. Em consonância, na perspectiva discursiva, entende-se que - ainda que esse gênero seja alçado no dizer parafrástico, pois ele contém o dizer do texto-fonte - ele permite, ou melhor, ele exige a voz daquele que se põe a resenhar. Assim, esse gênero possibilita uma certa abertura para o sujeito, mesmo que essa abertura seja determinada pelo discurso científico e pelo acadêmico. Dito de outro modo, a resenha pede a instauração de um dizer polissêmico, um dizer em que o autor não apenas se responsabilize pelo dito, mas também alce sua voz de modo que fique marcado o seu posicionamento acerca do texto-fonte.

\footnotetext{
${ }^{4}$ Não nos filiamos, aqui, a uma determinada corrente de estudo do gênero, por isso optamos por nomeá-los gêneros textuais discursivos. Apesar de trabalharmos a escrita acadêmica pautada pela caracterização do gênero, nosso foco recai sistematicamente sobre o discurso e o modo como o sujeito que inscreve textualmente ao escrever.

${ }^{5} \mathrm{O}$ fato de seguir um percurso semelhante não significa que haja uma metodologia estanque ou que os pesquisadores partem de um ponto fixo já pré-estabelecido. As atividades realizadas envolvem constantes reflexões sobre a própria prática, além disso as mudanças dos grupos participantes e as próprias variações existentes em cada grupo não possibilitariam o desenvolvimento de um método estanque, mas sim em constante reformulação.

${ }^{6}$ Sabe-se que na universidade é habitual a produção de resenhas acadêmicas que tomem como base objetos culturais tipicamente constituídos de relações de atividades humanas dessa esfera. No entanto, o objeto de nossa proposta de produção foi a resenha de uma matéria jornalística. Justificamos nossa escolha tendo em vista dois critérios: i) o tempo disponível para o aluno poder ler o texto-fonte e posteriormente produzir a resenha dentro do horário de atendimento do LABEAL, e, ainda, receber uma devolutiva de sua produção; ii) iniciarmos com textos menos complexos, mas não deixando de abordar as características do gênero, para, a posteriori, adentrar em textos mais complexos, preferencialmente aqueles trazidos pelos próprios estudantes, e que estejam sendo objetos de suas escritas na esfera da universidade
} 
A produção dessa resenha se deu no Laboratório após a leitura da reportagem da Revista Veja. Em seguida, os coordenadores do projeto fizeram uma leitura em conjunto com o aluno apontando questões pertinentes para o processo de reescrita, tanto de ordem discursiva como de ordem linguística ${ }^{7}$. Para a análise, chamaremos o sujeito na posição-autor resenhista de Participante 01 (P01). Tomando como pressuposto o modo de funcionamento das produções no LABEAL, trazemos o primeiro recorte do corpus selecionado para desenvolver uma análise preliminar ${ }^{8}$.

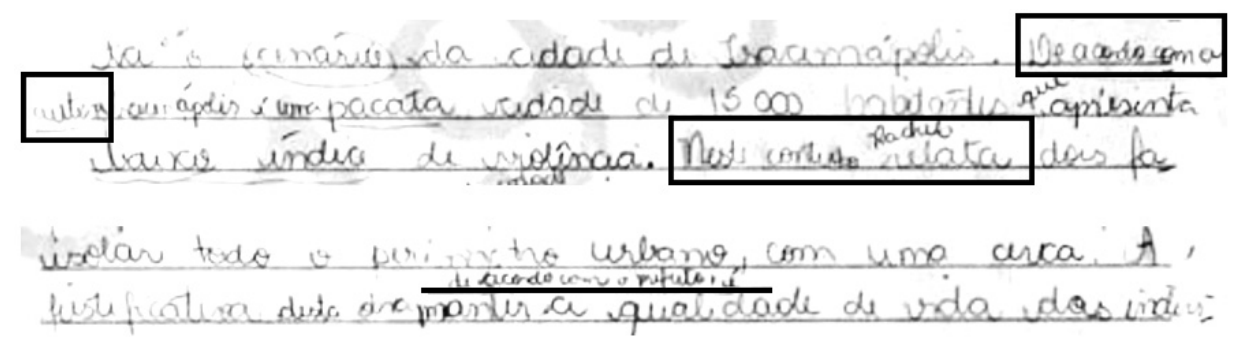

Imagem 1: Excertos ( 1 e 2) da primeira escrita da resenha P01 (grifos nossos).

Fonte: Arquivo dos autores

Nesse primeiro recorte, percebe-se, já na primeira escrita da resenha, marcas que podem se caracterizar como elementos que foram adicionados posteriormente à elaboração do texto: "De acordo com a autora"; "Neste contexto Rachel”; "de acordo com o prefeito". Esse aspecto, ainda que seja somente uma das possibilidades dada as condições de produção do LABEAL, visto que ao mesmo tempo em que alguns participantes escrevem seus textos outros recebem sugestões dos mediadores, indica uma possível compreensão do funcionamento do gênero. Além disso, mostra que o participante passa a perceber questões de autoria, porque já situa qual dizer não é seu, e já abre espaço para o seu posicionamento sobre o texto-fonte.

Chamamos a atenção, também, para outros aspectos mais relacionados com a produção de efeitos de sentido, mas que também reverberam que o sujeito reproduz o posicionamento do texto-fonte acerca da cidade e parece assumi-lo como seu. Assim, logo no início dessa primeira produção escrita, ressaltamos a sequência discursiva "O texto 'Atrás dos Muros' de Rachel Verano, retrata $o$ cenário da cidade de Iracemápolis". O uso do termo “o cenário” pode produzir o sentido de que o discurso da autora, Rachel Verano, sobre a cidade, constitui de fato o cenário da cidade, sendo este um único cenário. É diferente dizer, por exemplo: "O texto 'Atrás dos Muros’ de Rachel Verano retrata um dos cenários da cidade de Iracemápolis”, ainda que nessa construção o sentido de que Rachel retrata um cenário (não o único, mas que de fato retrata um), permanece. E, ainda, é diferente dizer "No texto 'Atrás dos Muros' Rachel Verano apresenta sua visão sobre o cenário da cidade de Iracemáopolis", que proporciona ainda mais um distanciamento daquele que diz com relação às informações apresentadas pelo texto-fonte e que constitui, em larga escala, as formas de escrita acadêmica.

Destacamos, também, enunciados que se estabelecem na relação entre a resenha e texto-fonte e que podem auxiliar na compreensão dos movimentos do sujeito em sua escrita para perceber maior ou menor gesto que leva esse dizer à assunção à autoria. Esses enunciados aparecem como efeito metafórico, sendo este um fenômeno semântico que se configura como deslizamento de sentido de um enunciado para outro. Em consonância com Orlandi (1996, p. 81), "[fala-se] a mesma língua mas se fala diferente. Pelo efeito metafórico. Esse deslize, próprio da ordem do simbólico, é o lugar da interpretação, da ideologia e da historicidade”. Assim, apontamos como pode se dar o efeito metafórico entre os dois enunciados:

\footnotetext{
${ }^{7}$ Chamamos de ordem linguística, aqui, o que diz respeito aos aspectos formais da língua.

${ }^{8}$ A resenha na íntegra encontra-se disponível em anexos.
} 
Em todo este ano, foram registrados apenas sete roubos. Ainda Neste contexto, Rachel relata dois fatos 'surpreendentes', o primeiro assim, Iracemápolis deixou-se contaminar pelo mesmo pavor que relacionado à quantidade de presos, sendo apenas 3 pessoas e o aflige as metrópoles e tomou uma providência inusitada para segundo ao número de roubos registrado no ano XX, que somou em manter a bandidagem longe de suas ruas. Nos próximos meses, 7. Mas o curioso não para nessa instância, pois o prefeito de será a primeira cidade inteiramente cercada de que se tem notícia Iracemápolis está tocando uma obra para isolar todo o perímetro no país. (grifos nossos). urbano, com uma cerca. (grifos nossos)

Quadro 1: Relação do texto-fonte com a primeira escrita

Fonte: Transcrição de arquivo dos autores

O sujeito, ao dizer que o "curioso" não é apenas o baixo indíce de violência, mas também a atitude do prefeito em cercar a cidade, estabelece uma relação semântica com o texto-fonte que afirma que o prefeito "tomou uma providência inusitada". Percebe-se que essa substituição contextual, entre "tomou uma providência" e "mas o curioso", é constitutiva do sentido de ambas as sentenças, já que algo inusitado é, também, algo curioso. É nesse sentido que tais enunciados evidenciam o efeito metafórico constitutivo de todo o dizer e que, também, em consonância com Foucault (2013 [1969]), evidenciam a característica do enunciado que se constitui em relação a outros. Além disso, esse movimento se caracteriza como uma inscrição do sujeito em seu dizer, pois ele julga a atitude do prefeito como curiosa e, desse modo, se mostra mais presente na resenha. Em outras palavras, o sujeito não marca o dizer como não dele, pelo o que se intui, então, que o dito consiste em seu posicionamento.

Com relação a essa (não) marcação do dizer, nos remetemos a Authier-Revuz (1990), que trabalha com heterogeneidades enunciativas. A autora afirma que a formulação do dizer consiste em uma negociação entre a heterogeneidade constitutiva e a heterogeneidade mostrada. Isto é, o sujeito que diz está sempre negociando o seu dizer que se sustenta, inexoravelmente, em uma relação com o discurso do outro e com o seu próprio dizer. Para isso, ele apaga algumas marcações, que assume como suas (mesmo que constituídas pelo outro) e marca explicitamente outros dizeres, justamente para dizer "isso aqui, quem disse, não fui eu”; assim, marca explicitamente o outro em seu texto para dizer que o resto, o que sobra, é "propriedade sua".

Nessa perspectiva, é importante salientar que a heterogeneidade é constitutiva do discurso e do sujeito, isto é, "[...] o discurso é construído a partir do discurso do outro, que é o ‘já dito’ sobre o qual qualquer discurso se constrói, ou seja, numa relação de alteridade." (BRAGA; ACOSTA-PEREIRA, 2016, p. 1514). Nesse sentido, Authier-Revuz (1990) diferencia a heterogeneidade constitutiva da mostrada no discurso, sendo esta a que expõe o outro na materialidade do discurso e aquela a que assenta o dizer do eu na relação com outros dizeres - o já dito - de forma a apagar esse outro. Além disso, a autora ainda propõe uma subdivisão entre heterogeneidade mostrada marcada e não marcada, em que a primeira consiste em uma referenciação visível do outro no dito, como a citação direta, e a segunda se caracteriza pela presença do outro com ausência de marcações diretas, pelo discurso indireto livre, ironia, metáfora, por exemplo.

Trazemos Authier-Revuz (1990) justamente para pensar sobre a sequência discursiva "mas o curioso", que seria um deslocamento do texto-fonte e que não está marcado na resenha do P01. Em outras palavras, ao não marcar o texto-fonte como referência a essa caracterização (como curiosa) do acontecimento na cidade de Iracemápolis, o sujeito-resenhista assume que esse é o seu posicionamento, e compreendemos que essa pode ter sido uma negociação inconsciente com a heterogeneidade constitutiva do discurso. Isto é, o sujeito assumiu aquele posicionamento como seu, ainda que ele esteja constituído nessa relação com o dizer do outro.

Algo semelhante ocorre na sequência discursiva, como vemos no recorte abaixo: 
Neste contexto, Rachel relata dois fatos 'surpreendentes', o primeiro relacionado à quantidade de presos, sendo apenas 3 pessoas e o segundo ao número de roubos registrado no ano XX, que somou em 7. (grifos nossos).

Quadro 2: Recorte constitutivo de fragmento da primeira escrita

Fonte: Transcrição de arquivo dos autores

O adjetivo "surpreendentes" não aparece explicitamente no texto-fonte, mas está em relação com os enunciados da autora Rachel Verano, e seu posicionamento com relação à violência em Iracemápolis. É possível perceber tal ligação pelos enunciados do textofonte: "Iracemapólis é uma pacata cidade de 15.000 habitantes [...] que se gaba de contar nos dedos de uma mão o número de presos[...]" e "A violência é coisa tão rara lá" (grifos nossos), que enfatizam a pouca violência como algo expressivo, "surpreendente". O sujeito, ao utilizar esse termo ("surpreendente”), e, como já visto, ao provocar esse efeito metafórico, corrobora a voz do texto-fonte, ou seja, assume a mesma posição ideológica perceptível por essas relações discursivas que constituem tanto a resenha quanto o texto-fonte. Nesse sentido, o uso desse adjetivo pode marcar a singularidade desse dizer, já que ele aponta para a classificação do que o sujeito que enuncia considera surpreendente e, consequentemente, para seu posicionamento ideológico.

No que tange à questão da heterogeneidade enunciativa, como já dito, a sequência discursiva "surpreendentes", de forma semelhante a "mas o curioso", se relaciona ao texto-fonte. Nesse caso, mesmo dialogando com o texto-fonte, ela pode ser considerada como um ponto de heterogeneidade constitutiva do discurso daquele que se põe a resenhar.

Dessa forma, caracterizamos na sequência discursiva o registro de "surpreendentes" como um ponto de heterogeneidade constitutiva no dizer do resenhista afeto pelo dizer do texto-fonte. O uso das aspas pelo resenhista poderia num primeiro momento levar-nos a pensar em heterogeneidade mostrada marcada. No entanto, numa leitura mais atenta percebe-se que o adjetivo "surpreendente" não faz as vezes de discurso direto retirado do texto-fonte. Assim, o uso das aspas - nesse caso - não enseja marcar o outro em seu próprio discurso, ao contrário, objetiva, justamente, chamar a atenção para a sua própria voz. É como se ele [o resenhista] fizesse uma glosa ao seu próprio dizer para enfatizar sua posição acerca do que considera a respeito dos fatos relatados pela autora do texto-fonte. Aqui, a negociação se faz às avessas do que previu Authier-Revuz (1990); as aspas marcam a incidência do dizer do sujeito sobre seu próprio dizer: chamar a atenção por meio do adjetivo "surpreendentes" com aspas marca duplamente o sujeito ao seu texto e o reafirma nesse lugar de escrever uma resenha aos modos do que compreende ser o funcionamento desse gênero.

No que consiste à heterogeneidade mostrada, trata-se de pontos dentro da enunciação que remete "[...] a um alhures, a um exterior explicitamente marcado ou dado a especificar [...] ou seja, a designação de um exterior específico é, através de cada marca de distância, uma operação de constituição de identidade para o discurso." (AUTHIER-REVUZ, 1990, p. 31).

Ainda sob a perspectiva proposta por Authier-Revuz (1990), trazemos outros recortes já com os destaques que são pertinentes para a análise da heterogeneidade mostrada,

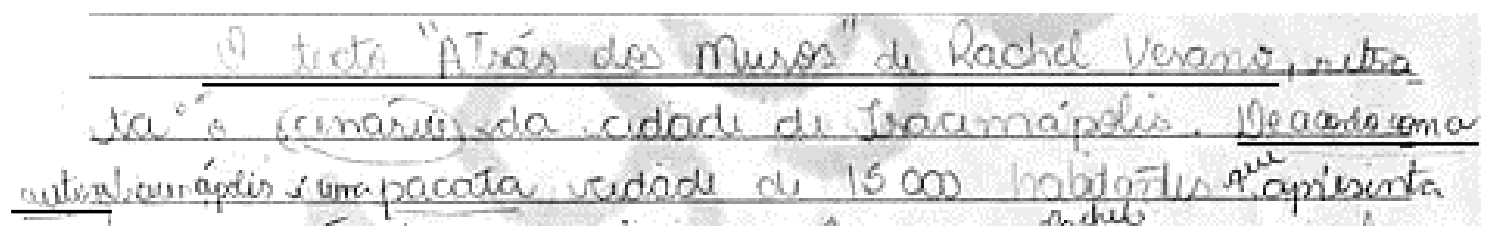

Imagem 2: Excerto (3) da primeira escrita da resenha P01 (grifos nossos)

Fonte: Arquivo dos autores

e também no penúltimo: 


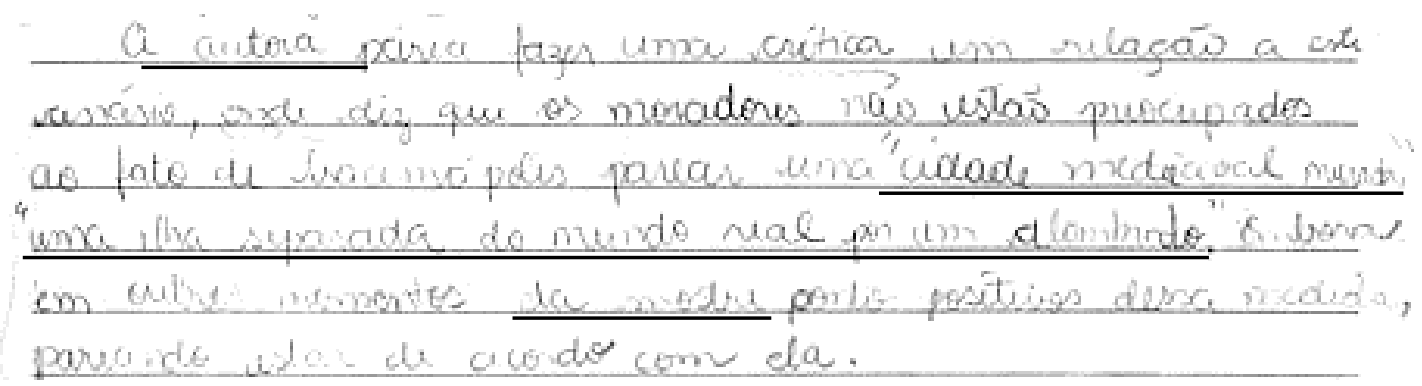

Imagem 3: Excerto (4) da primeira escrita da resenha P01 (grifos nossos)

Fonte: Arquivo dos autores

Essas sequências discursivas grifadas, "O texto 'Atrás dos Muros' de Rachel Verano", "De acordo com a autora”, "A autora” são referências explícitas ao texto-fonte, bem como as citações diretas "cidade medieval murada" e "uma ilha separada do mundo real por um alambrado", e constituem pontos de heterogeneidade mostrada marcada na resenha. Os usos de referências e citações diretas são recorrentes em textos acadêmicos e produzem um distanciamento daquele que diz, identificando de qual lugar (ou lugares) vem aquele dizer. É nesse sentido que problematizamos não o uso, ou melhor, a explicitação das referências, mas a produção textual que se limita a essa forma de dizer e que não instaura maiores relações de autonomia do sujeito-autor com relação ao texto-fonte.

Atentamos, agora, para o último parágrafo da resenha, em que se percebe um jogo entre a heterogeneidade marcada e a constitutiva na mesma sequência discursiva, de modo como não vimos em Authier-Revuz (1990):

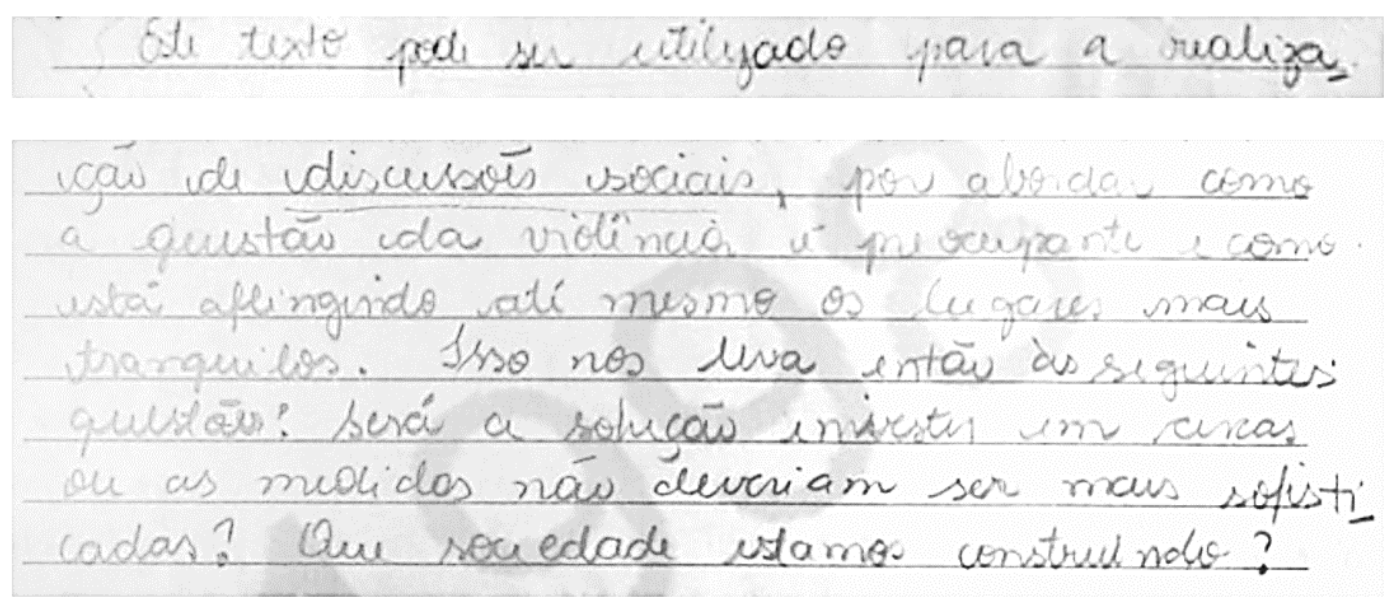

Imagem 4: Excerto (5) da primeira escrita da resenha P01

Fonte: Arquivo dos autores

Chamamos a atenção para a abertura desse parágrafo que se inicia por um ponto de heterogeneidade mostrada não marcada e que remete ao dizer global do texto-fonte: "Este texto"; o que podemos entender como "todo o texto" ou, ainda, "o assunto desenvolvido no texto traz à tona a questão da". No entanto, a seguir o sujeito na posição de autor da resenha relaciona a temática posta pelo textofonte ao seu universo axiológico tomado por "tudo" ou pelo "pouco" que já sabe/conhece sobre questões que atravessam o tema. É a partir disso que ele tomado, também, por outros discursos - pelo já dito - constitui o seu dizer ao questionar as tais "soluções de segurança” ou, ainda, ao questionar, num viés mais sociológico, a construção da sociedade atual da qual ele faz parte e que, também, se co-responsabiliza por construí-la: “Que sociedade [nós] estamos construindo?”. O discurso sobre violência versus segurança, por exemplo, está presente em diversas formações discursivas e requer sempre a presença do perigo que vem do outro. Um discurso que vem se (re)constituindo historicamente e que traz no bojo uma série de outras questões sociais. Podemos relacionar, no limite, esse parágrafo a dizeres cristalizados em nossa sociedade como "Diga não à violência", "Violência gera violência", entre outros que procuram pensar sobre a violência na sociedade contemporânea. 
No que tange à inscrição autoral, percebe-se que o sujeito, aqui, se afasta do texto-fonte para trazer outra opinião sobre o assunto abordado na reportagem. Nesse sentido, esse posicionamento pode se caracterizar como o momento em que o sujeito se inscreve em seu dizer, isto é, em que ele se coloca em um movimento que busca o efeito de fecho e unidade e que constitui mais explicitamente a função-autor. Além disso, ao mesmo tempo em que se afasta do texto-fonte, esse parágrafo se aproxima desses dizeres cristalizados sobre a violência, aspecto que ressalta a heterogeneidade constitutiva do discurso e que evidencia a função-autor como implicada pelo dizer do outro.

Para observar o processo de constituição da autoria do sujeito, é interessante atentar para a reescrita e os movimentos, deslocamentos que ela suscita. Nesse sentido, a proposta é perceber como se dá a reescrita tendo em vista os apontamentos que os mediadores do projeto fazem sobre o gênero acadêmico selecionado ${ }^{9}$. De início, ressaltamos que, tanto na primeira como na segunda produção escrita, a resenha do Participante 01 apresenta o título "Resenha do texto: Atrás dos Muros", e que essa marca linguística reflete as condições de produção da escrita da resenha acadêmica no Laboratório, já que, em outras situações em que a produção desse gênero é demandada na academia, acreditamos que essa forma de título não apareceria. É muito comum ver a própria referência do texto-fonte antes da apresentação da resenha, característica essa que não aparece na resenha. Em acréscimo, nos voltamos para este deslocamento que aparece no primeiro parágrafo:

\begin{tabular}{l|l}
\multicolumn{1}{c|}{$1^{\mathrm{a} e s c r i t a}$} & \multicolumn{1}{|c}{ Reescrita } \\
\hline $\begin{array}{l}\text { O texto ‘Atrás dos Muros' de Rachel Verano, retrata o cenário } \\
\text { da cidade de Iracemápolis. (grifos nossos). }\end{array}$ & $\begin{array}{l}\text { O texto ‘Atrás dos Muros' de Rachel Verano, retrata a } \\
\text { construção de uma cerca ao redor da cidade de } \\
\text { Iracemápolis. (grifos nossos). }\end{array}$
\end{tabular}

Quadro 3: Relação (1) da primeira escrita com a reescrita

Fonte: Transcrição de arquivo dos autores

Como já visto, a construção "o cenário da cidade de Iracemápolis" aponta para uma visão transparente da linguagem na qual a autora, Rachel Verano, apresentaria de fato o cenário do município como o único em seu texto. Já na reescrita, percebe-se um distanciamento do autor com relação a essa informação, e agora ele explicita mais especificamente o que é tratado no texto levando a um outro efeito de sentido. Na segunda construção sintática, o foco está na construção da cerca na cidade e que a reportagem trata justamente desse cercamento (e não do cenário da cidade). Essa mudança na forma de inscrição reverbera em todo o primeiro parágrafo, que parece assumir um aspecto mais autoral se comparado à primeira produção.

\begin{tabular}{|c|c|}
\hline $1^{\text {a }}$ escrita & Reescrita \\
\hline $\begin{array}{l}\text { O texto 'Atrás dos Muros' de Rachel Verano, retrata o cenário } \\
\text { da cidade de Iracemápolis. De acordo com a autora, } \\
\text { Iracemápolis é uma pacata cidade de } 15.000 \text { habitantes que } \\
\text { apresenta baixo índice de violência. Neste contexto relata dois } \\
\text { fatos "surpreendentes", o primeiro relacionado à quantidade } \\
\text { de presos, sendo apenas } 3 \text { pessoas e o segundo ao número de } \\
\text { roubos registrado no ano XX, que somou em } 7 \text {. Mas o curioso } \\
\text { não para nesta instância, pois o prefeito de Iracemápolis está } \\
\text { tocando uma obra para isolar todo o perímetro urbano, com } \\
\text { uma cerca. A justificativa desta obra manter a qualidade de } \\
\text { vida dos indivíduos que ali habitam e para evitar problemas } \\
\text { futuros de segurança. }\end{array}$ & $\begin{array}{l}\text { O texto 'Atrás dos Muros' de Rachel Verano, retrata a } \\
\text { construção de uma cerca ao redor da cidade de Iracemápolis. } \\
\text { De acordo com a autora, o intuito da cerca é manter a } \\
\text { "bandidagem" longe das ruas da cidade. }\end{array}$ \\
\hline
\end{tabular}

Quadro 4: Relação (2) da primeira escrita com a reescrita

Fonte: Transcrição de arquivo dos autores

${ }^{9}$ A reescrita na íntegra encontra-se disponível em anexos. 
O primeiro parágrafo da primeira escrita segue mais o fluxo do texto-fonte, com semelhante ordem de apresentação das informações e das sentenças. Já na reescrita, esse parágrafo aparece como uma sintetização do foco principal do texto-fonte (o cercamento da cidade de Iracemápolis) para, na sequência da resenha, apresentar outras informações. Caracterizamos esse deslocamento como um efeito autoral, já que essa forma de dizer da reescrita se distancia mais da forma de dizer texto-fonte, ou seja, se estabelece em uma relação mais autônoma. De forma avessa, ao mesmo tempo em que o sujeito que diz manipula mais livremente as informações, os adjetivos "curioso" e "supreendentes", que poderiam marcar mais seu posicionamento, desaparecem na reescrita. Ao invés desses termos, o sujeito inclui o substantivo "bandidagem” já grafado com aspas para acentuar a referência à reportagem e que se caracteriza como um ponto de heterogeneidade mostrada marcada, aos modos como classifica Authier-Revuz (1990).

No segundo parágrafo da reescrita, o sujeito-resenhista apresenta informações sobre a cidade de Iracemápolis, dados presentes, anteriormente, no primeiro parágrafo na $1^{\text {a }}$ escrita, e evidencia a demarcação das vozes da autora do texto-fonte e do prefeito.

\begin{tabular}{l|l}
\multicolumn{1}{c|}{$1^{\text {aa escrita }}$} & \multicolumn{1}{c}{ Reescrita } \\
\hline $\begin{array}{l}\text { Até o momento da publicação a cerca ocupa } 500 \text { metros, onde } \\
\text { divide um bairro de classe média de uma movimentada } \\
\text { rodovia. Foi neste local onde ocorreu o último e mais violento } \\
\text { roubo, e a vítima diz que com a cerca sente-se bem mais } \\
\text { protegido. }\end{array}$ & $\begin{array}{l}\text { Segundo Verano, Iracemápolis é uma cidade de 15000 } \\
\text { habitantes que apresenta baixo índice de violência. Para } \\
\text { justificar o baixo índice de violência, a autora apresenta dois } \\
\text { fatos da cidade, o primeiro relacionado ao número de presos, } \\
\text { somando 3, e aos 7 roubos que ocorreram ao longo do ano. De } \\
\text { acordo com o texto, mesmo com a baixa violência a população } \\
\text { aflinge as metrópoles'. Diante deste contexto, o prefeito da } \\
\text { cidadem Cláudio Consenza, está tocando uma obra para isolar } \\
\text { todo o perímetro urbano, com um alambrado de 2,5 metros de } \\
\text { altura num percurso de quase 9 quilômetros. De acordo com } \\
\text { a fala do prefeito, apresentada na obra, só assim será possível } \\
\text { manter a qualidade de vida dos indivíduos que ali habitam. } \\
\text { (grifos nossos). }\end{array}$
\end{tabular}

Quadro 5: Relação (3) da primeira escrita com a reescrita

Fonte: Transcrição de arquivo dos autores

Conforme destacamos em negrito, é perceptível a maior quantidade de pontos de heterogeneidade mostrada marcada na reescrita quando se compara à $1^{\text {a }}$ escrita. Assim, as expressões, "Segundo Verano", "a autora apresenta", "de acordo com o texto" e "De acordo com a fala do prefeito, apresentada na obra", referências diretas ao texto-fonte, bem como a citação "deixou-se contaminar pelo pavor que aflinge as metrópoles", podem ser caracterizadas como pontos de heterogeneidade mostrada marcada (AUTHIERREVUZ, 1990). Nesse sentido, faz-se mister refletir sobre o que parece um excesso do uso dessas marcações, visto que há mais do dizer do outro e menos de seu dizer enquanto sujeito-autor. Dito de outro modo, parece-nos que ao "compreender" o modo de funcionamento e construção do gênero resenha, ele [o resenhista] faz mais uso do dizer do outro e fica com menor presença de sua voz em seu próprio texto.

Ainda, a sequência discursiva "Para justificar o baixo índice de violência, a autora apresenta dois fatos..." aponta para a noção de que o sujeito que diz já não toma o índice de violência como verdade posta por Rachel, mas ressalta a apresentação de dados que a autora exibe na reportagem e que evidenciam esse baixo índice. Esse distanciamento tomado pelo sujeito parece ser mesmo recorrente da escrita acadêmica na qual sempre que se fala algo se fala com base em dados, em já-ditos observáveis, para a sustentação do efeito de uma escrita mais neutra e objetiva.

Essa necessidade de apresentar evidências, que se relaciona com a necessidade de instaurar enunciados no discurso verdadeiro na universidade, é perceptível também no deslocamento que o sujeito faz no terceiro parágrafo da reescrita. 


\begin{tabular}{l|l}
\multicolumn{1}{c|}{$1^{\text {a escrita }}$} & \multicolumn{1}{c}{ Reescrita } \\
\hline $\begin{array}{l}\text { A autora parece fazer uma crítica em relação a este cenário, } \\
\text { onde diz que os moradores não estão preocupados ao fato de } \\
\text { Iracemápolis parecer uma 'cidade medieval murada', 'uma ilha } \\
\text { estenário, dizendo que os moradores não estão preocupados } \\
\text { ao fato de Iracemápolis parecer 'uma cidade medieval murada', } \\
\text { 'uma ilha separada do mundo real por um alambrado', embora } \\
\text { outros momentos ela mostre pontos positivos dessa } \\
\text { medida, parecendo estar de acordo com ela. (grifos nossos). }\end{array}$ & $\begin{array}{l}\text { medida, relatando que com ela os moradores sentem-se } \\
\text { mais tranquilos. (grifos nossos). }\end{array}$
\end{tabular}

Quadro 6: Relação (4) da primeira escrita com a reescrita

Fonte: Transcrição de arquivo dos autores

Nesse parágrafo, como já dito, a mudança produzida em relação à forma de escrever parece estar mais presa a uma preocupação de atender aos pressupostos da escrita acadêmica - que investe numa forma objetiva de apontar o dizer do outro e, assim, não marcar a subjetividade daquele que escreve nessa discursividade. O sujeito que diz procura se posicionar em relação ao texto-fonte, afirmando que o posicionamento da autora da reportagem é contraditório: ora ela tende a ser favorável, ora contra o cercamento da cidade. Essa declaração do sujeito-autor está presente em ambas as produções escritas, porém, conforme ressaltado em negrito, apontamos um deslocamento no que tange à adequação do dizer na esfera acadêmica. Dizer "Embora em outros momentos ela mostre pontos positivos dessa medida, parecendo estar de acordo com ela" produz diferentes efeitos de sentido se comparado com "embora em outros momentos ela aponte pontos positivos dessa medida, relatando que com ela os moradores sentem-sem mais tranquilos". Essa última sentença presente na reescrita apresenta o motivo pelo qual a autora do texto-fonte parece estar em um posicionamento também favorável ao cercamento da cidade. Esse movimento se caracteriza como um ponto de heterogeneidade mostrada não marcada através do uso do discurso indireto livre - nos termos de Authier-Revuz (1990) - e procura sustentar os argumentos da posição-sujeito resenhista sobre um possível posicionamento dúbio de Rachel. Em outras palavras, o sujeito-autor da resenha procura sustentar seus argumentos com base no que está dito no texto-fonte sobre a tranquilidade que a cerca proporciona aos moradores através do dicurso indireto livre, e constitui a marca do embasamento característica da escrita na academia.

Ainda sobre esse parágrafo, questionamos: há, de fato, nesse excerto um posicionamento mais autoral do que na primeira escrita ou, apenas, maior embasamento das informações? Esse questionamento irrompe pelo fato de que parece haver pouca mudança com relação ao posicionamento do sujeito na $1^{\text {a }}$ e $2^{\text {a }}$ escrita e, ainda assim, esta mudança está muito mais relacionada ao acréscimo de informações que sustentam os argumentos com base no texto-fonte do que a apresentação de um posicionamento mais autônomo e crítico. Em outras palavras, o sujeito não assume um posicionamento que se desprende daquilo que é dito no texto-fonte.

O quarto parágrafo permanece muito semelhante nas duas produções escritas. Porém, assinalamos alguns movimentos.

\begin{tabular}{|c|c|}
\hline $1^{\text {a }}$ escrita & Reescrita \\
\hline $\begin{array}{l}\text { Este texto pode ser utilizado para a realização de discussões } \\
\text { sociais, por abordar como a questão da violência é preocupante } \\
\text { e como está aflingindo até mesmo os lugares mais tranquilos. } \\
\text { Isso nos leva então às seguintes questões: será a solução } \\
\text { investir em cercas ou as medidas não deveriam ser mais } \\
\text { sofisticadas? Que sociedade estamos construindo? (grifos } \\
\text { nossos). }\end{array}$ & $\begin{array}{l}\text { Este texto pode ser utilizado para a realização de discussões } \\
\text { sociais, por abordar como a questão da violência é preocupante } \\
\text { e como está aflingindo até mesmo os lugares mais tranquilos. } \\
\text { Além disso, pode discutir quais as melhores medidas a } \\
\text { serem tomadas para que haja a diminuição da violência nas } \\
\text { cidades e a melhoria da qualidade de vida. (grifos nossos). }\end{array}$ \\
\hline
\end{tabular}


Percebemos um deslocamento no que tange à inscrição do sujeito como autor de seu dizer na reescrita desse parágrafo, isto é, o sujeito parece se ausentar mais de seu texto. Isso porque, enquanto na primeira escrita a questão colocada pelo sujeito aponta para a existência de medidas mais sofisticadas que a construção de cercas, na reescrita há um maior distanciamento com a discussão de quais seriam as melhores medidas para diminuir a violência e melhorar a qualidade de vida. A omissão da última pergunta presente na $1^{\text {a }}$ escrita (Que sociedade estamos construindo?) também produz um maior distanciamento da posição-sujeito resenhista sobre a atitude do prefeito em cercar a cidade e, consequentemente, de seu posicionamento sobre tal medida. Ressaltamos, porém, que nas duas escritas mantém-se a referência à alteridade, tanto ao dizer do texto-fonte de forma geral quanto a discursos generelizantes sobre violência e segurança que estão presentes na sociedade contemporânea, mas que surgem como constituvivos de seu próprio discurso e, por isso, se constituem numa dupla face entre a heterogeneidade mostrada e a heterogenenidade constitutiva, respectivamente (AUTHIER-REVUZ, 1990).

Para sintetizar, é relevante destacar que a reescrita, que está mais próxima do gênero resenha acadêmica, apresenta maior demarcação dos dizeres das diferentes posições-sujeito, ou seja, mais quantidade de pontos de heterogeneidade mostrada marcada e não marcada. Em consonância com Authier-Revuz (1990), ressaltamos que essa negociação da heterogeneidade constitutiva com a heterogeneidade mostrada constitui o nosso dizer e o uso de mais ou menos pontos de heterogeneidade mostrada pode se configurar como uma compreensão inconsciente do outro que constitui o nosso discurso. Porém, a reescrita da resenha parece estar limitada à explicitação da voz do outro, aspecto que corrobora o apagamento do sujeito enquanto autor. Dito de outro modo, a voz que se explicita é a do outro, e a do próprio sujeito-resenhista é escamoteada, configurando-o como observador de seu dizer (AUTHIER-REVUZ, 1990). Assim, podemos assinalar a heterogeneidade mostrada como característica da escrita acadêmica que pode causar, quando o texto se limita ao seu uso, dificuldades na assunção à autoria do sujeito, pois se o sujeito que diz, diz só sobre o dizer do outro, menos ele aparece como autor, ainda que a função-autor esteja sempre presente.

\section{CONSIDERAÇÕES FINAIS}

No percurso traçado, buscamos observar o funcionamento do discurso em uma resenha produzida no LABEAL em seu processo de escrita e reescrita, tendo em vista a inscrição do sujeito na função-autor. Como já visto, autor é aquele que organiza o dizer gerando um efeito de unidade (completude) e se responsabiliza pelo texto produzido. Assim, o sujeito que se inscreve na resenha se constitui na função-autor justamente por essa visão pulverizada da autoria enquanto gesto de interpretação, posição que organiza, evidencia, silencia informações e que dá forma ao texto.

Na resenha, nota-se uma dificuldade em se posicionar e, ao que parece, o próprio gênero resenha acadêmica se insere em uma formação discursiva característica da escrita nessa esfera (no entre-meio entre o se ausentar pelo resumo e o se posicionar criticamente), em um espaço que o sujeito que diz se apropria do dizer do outro e explicita mais ou menos a sua voz. Pela análise preliminar, percebe-se na reescrita da resenha um distanciamento da forma sintática do texto-fonte, ou seja, do modo como as informações foram organizadas, característica que aponta para um maior movimento autoral. Entretanto, é também na reescrita que aparecem mais pontos de heterogeneidade mostrada (AUTHIER-REVUZ, 1990), e que a resenha parece se limitar à explicitação do outro. Além disso, alguns elementos autorais da $1^{\text {a }}$ escrita se modalizam de tal forma que, na reescrita, não parecem se constituir como posicionamento crítico. Essas questões nos levam a refletir sobre o nosso trabalho no LABEAL e sobre a constituição do discurso científico (que insiste na objetividade do referente) difundido no e pelo discurso acadêmico, este último atravessado pelo discurso pedagógico.

Para concluir, em uma primeira instância, pode-se acordar que o processo de escrita acadêmica consiste na tentativa de "conter" a heterogeneidade constitutiva do discurso e do sujeito, na luta pela transparência da linguagem e dos sentidos (únicos) em nome do discurso científico. Nesse processo, em que a objetividade é almejada, o sujeito procura se constituir assumindo diferentes posições, conforme as condições de produção, e tentando se situar no entre-meio aceitável (possível de ser dito) que configura a função-autor na universidade. 


\section{REFERÊNCIAS}

AUTHIER-REVUZ, J. Heterogeneidade(s) enunciativas(s). Tradução de Celene M. Cruz e João Wanderley Geraldi. Caderno de Estudos Linguísticos, Campinas, v.19, p.25-42, jul./dez.1990.

BALTAR, M. A. R.; CERUTTI-RIZZATTI, M. E.; ZANDOMENEGO, D. Leitura e produção textual acadêmica I. Florianópolis: LLV/CCE/UFSC, 2011.

BRAGA, S.; ACOSTA-PEREIRA, R. A inscrição do sujeito na escrita acadêmica numa perspectiva dialógica. Fórum Linguístico, Florianópolis, $\quad$ v. $\quad 13, \quad$ n. $\quad 3, \quad$ p. $\quad 1506-1524, \quad$ jul./set. $2016 . \quad$ Disponível em: <https://periodicos.ufsc.br/index.php/forum/article/view/1984-8412.2016v13n3p1506>. Acesso em: 15 dez. 2016.

FOUCAULT, M. Verdade e poder. In: . Microfísica do poder. Organização e tradução de Roberto Machado. Rio de Janeiro:

Edições Graal, 1989. [1979]. p. 1-14.

FOUCAULT, M. A ordem do discurso: aula inaugural no Collège de France, pronunciada em 2 de dezembro de 1970. Tradução de Laura Fraga de Almeida Sampaio. 22. ed. São Paulo: Edições Loyola, 2012. [1970].

FOUCAULT, M. A arqueologia do saber. Tradução de Luiz Felipe Baeta Neves. 8. ed. Rio de Janeiro: Forense Universitária, 2013. [1969].

LAGAZZI-RODRIGUES, S. Texto e autoria. In: ORLANDI, E. P.; LAGAZZI-RODRIGUES, S. (Org.). Introdução às ciências da linguagem: discurso e textualidade. 3. ed. Campinas, SP: Pontes Editores, 2015. p. 89-113.

LYOTARD, J. A condição pós-moderna. Tradução de Ricardo Corrêa Barbosa; posfácio: Silviano Santiago. 12. ed. Rio de Janeiro: José Olympio, 2009. [1979].

ORLANDI, E. P. Análise de discurso: princípios e procedimentos. 11.ed. Campinas, SP. Pontes Editores, 2013.

ORLANDI, E. P. Interpretação: autoria, leitura e efeitos do trabalho simbólico. Petrópolis, RJ: Vozes, 1996.

PÊCHEUX, M. Análise automática do discurso. In: GADET F.; HAK, T. (Org.). Por uma análise automática do discurso: uma introdução à obra de Michel Pêcheux. Campinas: Unicamp, 1990 [1969]. p. 61-161.

PÊCHEUX, M. Semântica e discurso: uma crítica à afirmação do óbvio. Tradução de Eni Puccinelli Orlandi et al. 5. ed. Campinas, SP: Editora da Unicamp, 2014. [1988].

PEREIRA, M. V. A escrita acadêmica do excessivo ao razoável. Revista Brasileira de Educação, v. 18 n. 52. p. 213-144. jan./mar. 2013. 


\section{ANEXO A: Transcrição da $1^{\text {a }}$ escrita da resenha do P01}

Resenha do texto: Atrás dos muros.

O texto “Atrás dos Muros” de Rachel Verano, retrata o cenário da cidade de Iracemápolis. De acordo com a autora Iracemápolis é uma pacata cidade de 15000 habitantes que apresenta baixo índice de violência. Neste contexto Rachel relata dois fatos 'surpreendentes' da cidade, o primeiro relacionado à quantidade de presos, sendo apenas 3 pessoas e o segundo, ao número de roubos registrado no ano XX, que somou em 7. Mas o curioso não para nesta instância, pois o prefeito de Iracemápolis está tocando uma obra para isolar todo o perímetro urbano, com uma cerca. A justificativa desta obra de acordo com o prefeito é manter a qualidade de vida dos indivíduos que ali habitam e para evitar problemas futuros de segurança.

Até o momento da publicação a cerca ocupa 500 metros, onde divide um bairro de classe média de uma movimentada rodovia. Foi neste local onde ocorreu o último e mais violento roubo e a vítima diz que com a cerca sentese bem mais protegido.

A autora parece fazer uma crítica em relação a este cenário, onde diz que os moradores não estão preocupados ao fato de Iracemápolis parecer uma "cidade medieval murada", "uma ilha separada do mundo real por um alambrado". Embora em outros momentos ela mostre pontos positivos dessa medida, parecendo estar de acordo com ela.

Este texto pode ser utilizado para a realização de discussões sociais, por abordar como a questão da violência é preocupante e como está aflingindo até mesmo os lugares mais tranquilos. Isso nos leva então às seguintes questões: será a solução investir em cercas ou as medidas não deveriam ser mais sofisticadas? Que sociedade estamos construindo? 


\section{ANEXO B: Transcrição da reescrita da resenha do P01}

Resenha do texto Atrás dos muros.

O texto "Atrás dos Muros" de Rachel Verano, retrata a construção de uma cerca ao redor da cidade de Iracemápolis. De acordo com a autora o intuito da cerca é manter a "bandidagem" longe das ruas da cidade.

Segundo Verano, Iracemápolis é uma cidade de 15000 habitantes que apresenta baixo índice de violência. Para justificar o baixo índice de violência, a autora apresenta dois fatos da cidade, o primeiro relacionado ao número de presos somando 3, e aos 7 roubos que ocorreram ao longo do ano. De acordo com o texto, mesmo com a baixa violência a população de Iracemápolis “deixou-se contaminar pelo pavor que aflinge as metrópoles”. Diante deste contexto, o prefeito da cidade, Cláudio Consenza, está tocando uma obra para isolar todo o perímetro urbano com um alambrado de 2,5 metros de altura, um percurso de quase 9 quilômetros. De acordo com a fala do prefeito, apresentada na obra, só assim será possível manter a qualidade de vida dos indivíduos que ali habitam.

Durante ao texto, a autora parece fazer uma crítica em relação a este cenário, dizendo que os moradores não estão preocupados ao fato de Iracemápolis parecer uma "cidade medieval murada", "uma ilha separada do mundo real por um alambrado", embora em outros momentos ela aponte pontos positivos dessa medida, relatando que com ela os moradores sentem-se mais tranquilos.

Este texto pode ser utilizado para a realização de discussões sociais, por abordar como a questão da violência é preocupante e como está aflingindo até mesmo os lugares mais tranquilos. Além disso, pode discutir quais as melhores medidas a serem tomadas para que haja a diminuição da violência nas cidades e a melhoria da qualidade de vida. 